\title{
Incommensurability as vagueness: a burden-shifting argument
}

Article

Accepted Version

Elson, L. (2017) Incommensurability as vagueness: a burdenshifting argument. Theoria, 83 (4). pp. 341-363. ISSN 17552567 doi: https://doi.org/10.1111/theo.12129 Available at https://centaur.reading.ac.uk/69536/

It is advisable to refer to the publisher's version if you intend to cite from the work. See Guidance on citing.

To link to this article DOI: http://dx.doi.org/10.1111/theo.12129

Publisher: Wiley

All outputs in CentAUR are protected by Intellectual Property Rights law, including copyright law. Copyright and IPR is retained by the creators or other copyright holders. Terms and conditions for use of this material are defined in the End User Agreement.

\section{www.reading.ac.uk/centaur}

\section{CentAUR}

Central Archive at the University of Reading

Reading's research outputs online 


\title{
Incommensurability as Vagueness: a Burden-Shifting Argument*
}

\author{
Luke Elson (luke.elson@ reading.ac.uk)
}

\section{Forthcoming in Theoria}

\begin{abstract}
Two options are 'incommensurate' when neither is better than the other, but they are not equally good. Typically, we will say that one option is better in some ways, and the other in others, but neither is better 'all things considered'. It is tempting to think that incommensurability is vagueness - that it is (perhaps) indeterminate which is better-but this 'vagueness view' of incommensurability has not proven popular. I set out the vagueness view and its implications in more detail, and argue that it can explain most of the puzzling features of incommensurability. This argument proceeds without appeal to John Broome's 'collapsing principle'.
\end{abstract}

When we compare options with respect to some value, it often seems that neither of two options is better, and they are not precisely equally good. If this is not an illusion, the options are incommensurate (or 'superhard' or 'incomparable'), and none of the trichotomous comparisons (betterness, worseness, equality) determinately holds between them. ${ }^{1}$

Incommensurability raises a number of puzzles. How do incommensurate options compare, if at all? And what are the constraints on rational choice between them? If, as I shall argue, incommensurability is vagueness, then vagueness in what we have reason to do is pervasive, not a mere theoretical curiosity. Rational choice under incommensurability is choice when it is indeterminate which of the trichotomous comparisons applies, rather than choice when none of them does.

\footnotetext{
*For discussion and comments, I am indebted to Dorit Bar-On, Ruth Chang, Ram Neta, John Roberts, Geoffrey Sayre-McCord, Walter Sinnott-Armstrong, Philip Stratton-Lake, Susan Wolf, to audiences in Charleston, Chapel Hill, Eindhoven, and Reading, and to several anonymous reviewers.

${ }^{1}$ I use the term 'incommensurability rather than 'incomparability' has in recent years been the more popular term, because on the vagueness view the options are comparable, albeit it is indeterminate which comparison holds between them.
} 
There are many classic examples of incommensurability. Who is more creative, Mozart or Michelangelo? Which is more impressive, Stonehenge or Salisbury Cathedral? Which is a better career, law or music? ${ }^{2}$

Such examples can mislead, if they imply that it is a rareified phenomenon or that it only affects significant choices. It can arise in almost any choice or evaluative comparison involving several virtues or 'dimensions' of goodness. Our main example is rather prosaic:

Holiday Choice. Katie lives in Sweden, and has decided to go on holiday to North America. This will be a significant expense for her. She has two salient options. Churchill in Manitoba is one of the best places in the world to see polar bears; it is exciting but expensive, not least because the roads don't go that far North. Florida beaches are less exciting, but make for a cheaper trip.

It is clear which holiday is better along each dimension (price, excitement, and so on). But for Katie the important question is altogether more difficult-which holiday is better for her all things considered? You may have the judgement (perhaps after some tweaking of the case) that each has something to be said for it, and that neither is overall better than the other.

So might they be precisely equally good? That this is not (always) the case may be seen with a 'Small Improvement Argument.' ${ }^{3}$ Call Churchill- the trip which is precisely similar to Churchill, but 5 Swedish kronor (about 50 Euro cents) more expensive. We are supposing that:

(1) Churchill is better than Churchill-.

(2) Churchill is neither better nor worse than Florida.

The suggestion is:

(2a) Churchill and Florida are equally good.

But (2a) together with (1) implies that Churchill- is worse than Florida. But the considerations that support (2) also seem to support a similar claim about Churchill-:

(3) Churchill- is neither better nor worse than Florida.

Denying (3) seems absurd, especially in light of (2). When comparing holidays along many dimensions, how could an arbitrarily small price increase 'tip the balance' in this fashion? This could happen, but only under very special circumstances. (3) gains support from the thought that had we encountered not Churchill but Churchill- first,

\footnotetext{
${ }^{2}$ The examples are due to Chang (2002), Broome (1997) and Raz (1986), respectively.

${ }^{3}$ For classic discussion of such arguments, see Sousa (1974).
} 
we would have judged that trip neither better nor worse than Florida. So claiming that Churchill and Florida are equally good does not resolve the puzzle, but merely shifts it to (3).

Eliminativists about incommensurability will claim that in such cases, one of (1)-(3) must be false, and we are likely in the grip of evaluative ignorance. It is clear that sometimes we do not know which of the trichotomous comparisons applies. Eliminativists claim that this is so in all apparent cases of incommensurability. Donald Regan defends such a thesis of 'complete comparability' concerning the Moorean good. ${ }^{4}$

If eliminativism is incorrect and there is some genuine incommensurability, then it is not merely ignorance:

Incommensurability. $\mathrm{a}$ and $\mathrm{b}$ are incommensurate with respect to some value $\mathrm{V}$ if and only if: it is neither determinately true that a is Ver than $b$, nor determinately true that $\mathrm{b}$ is Ver than a, nor determinately true that $\mathrm{a}$ and $\mathrm{b}$ are equally $\mathrm{V}$, and the comparison is not silly or malformed. ${ }^{5}$

This engenders a certain phenomenal instability or air of paradox. Even in prosaic examples such as Holiday Choice, it can be difficult to simultaneously entertain the thoughts that together make up the verdict that the options are incommensurate.

Rational choice between incommensurate options - such as that faced by Katie-is also puzzling. We may wish to say that she can choose either holiday, and in general it is intuitively plausible that one may choose either of two incommensurate options:

Arbitrary Choice Thesis. When two options are incommensurate with respect to some value, insofar as one is choosing in accord with that value, one may permissibly choose either.

After all, if a is no better than $b$ (with respect to V), then how could it be wrong (with respect to $\mathrm{V}$ ) to choose $\mathrm{b}$ over $\mathrm{a}$ ? And yet a similar point can be made against the thesis: how can it be permissible to choose either if they are not equally good? Whether the Arbitrary Choice Thesis is true or false, it requires either justification or an error theory. ${ }^{6}$

Unrestricted Arbitrary Choice engenders value-pumping, where a sequence of permitted choices amounts to an impermissible choice. This is because incommensurability

\footnotetext{
${ }^{4}$ Regan (1997), p. 129.

${ }^{5}$ The final clause sets aside cases of 'noncomparability', akin to "what's louder, my chair or this paragraph?" I won't try to cash out this clause more precisely, but I trust that its meaning is tolerably clear.

${ }^{6}$ Here and throughout, I assume a simple connection between the deontic and the evaluative: an option is permissible iff it is at least as good as all other options. I'm grateful to Philip Stratton-Lake for discussion of this point.
} 
is not transitive: a may be incommensurate with $\mathrm{b}$, and b incommensurate with $\mathrm{c}$, but a better than c. In Holiday Choice, Churchill is incommensurate with Florida, and Floria incommensurate with Churchill-, but Churchill is better than Churchill-.

Arbitrary Choice implies that it is permissible for Katie to choose Florida over Churchill, and then Churchill- over Florida. But this sequence of choices amounts to the impermissible choice of Churchill- over Churchill.

I will defend the vagueness view: if the holidays are incommensurate, it is indeterminate which is better for Katie. ${ }^{7}$ Perhaps, for example, Katie lacks determinate preferences and this indeterminacy 'infects' the evaluative comparison.

The argument is not that the vagueness view succeeds where other views fail. It is instead burden-shifting: we have good reason to believe that evaluative vagueness is anyway present, and that it can explain the main features of incommensurability, so competing views which posit a sui generis evaluative phenomenon face an explanatory burden. Given the theoretical parsimony of the vagueness view, we would need some reason to reject it as an account of incommensurability. ${ }^{8}$

In the next section, I sketch the main competing accounts of incommensurability. I argue that the success or failure of the vagueness view has come to be wrongly tied to the success or (likely) failure of a famous argument for it, due to John Broome. The independent plausibility of the view has been overlooked, and is my focus for the remainder of the paper.

I will often speak of evaluative comparisons between two 'options' or 'items'; these are intended to be read interchangeably. I will also be discussing both (permissible or impermissible) actions and (correct or incorrect) judgements about the relative value of options. A theory of incommensurability should both tell us what it is for two options to be incommensurate, and which choices are permissible between incommensurate options. These two questions are obviously related, but they do not amount to the same thing. We might hope that an answer to the second will be explained by an answer to the first; on the other hand, our philosophical intuitions about permissibility seem rather firmer than those about the nature of incommensurability, so they will inform our theorising about that issue question. (For an example of this, see the discussion of Chang's argument, below.)

\footnotetext{
${ }^{7}$ Here and throughout, I put this entirely in terms of indeterminacy, but almost everything can be recast in terms friendly to epistemicism about vagueness. There is a taxonomic complication, however. If incommensurability is vagueness and vagueness is ignorance, then it is unclear whether this should count as a form of the eliminativism discussed above.

${ }^{8}$ I'm grateful to John Broome for suggesting this interpretation of my argument.
} 


\section{Trichotomous Incomparabilism}

The 'orthodox' account of incommensurability is Trichotomous Incomparabilism. When two options are incommensurate, each of the trichotomous comparisons determinately fails to apply, and they are trichotomously incomparable:

Trichotomous Incomparability. $a$ and $b$ are trichotomously incomparable with respect to some value $\mathrm{V}$ when it is false that $\mathrm{a}$ is Ver than $\mathrm{b}$, and that $b$ is Ver than $a$, and false that $a$ and $b$ are equally V. Nevertheless, $a$ and $b$ are properly compared in terms of their Vness.

This can be fleshed out in quite different ways. Joseph Raz argues that often, no comparison applies in such cases, and the two options are simply incomparable. ${ }^{9}$ Ruth Chang argues that the options are comparable even when trichotomously incomparable: she defends the existence of a fourth comparison she calls 'parity', which holds in (at least some cases of) incommensurability. For Chang, the trichotomous comparisons do not exhaust the available comparisons. More formal versions of a parity account have been worked out by Wlodek Rabinowicz and Erik Carlson, respectively. ${ }^{10}$

It may seem like an abuse of terminology to group two such distinct views under the same heading, particularly because for Chang—but not for Raz-items may be incommensurate but nevertheless comparable (via the relation of parity). This, she claims, allows for an answer to the decision-theoretic questions: 'many choice situations in which justified choice seems precluded [ie, choice between incommensurate options] are in fact situations within the reach of practical reason. ${ }^{11}$

But orthodox views agree on this much: when two options are incommensurate, they are (at least sometimes) trichotomously incomparable, so each of the trichotomous comparisons determinately fails to apply. This can happen even though the options in question are 'of the right sort' to be compared by the value in question.

Whether or not the adherent of the vagueness view regards this as incoherent-for example, whether or not she thinks it a conceptual truth that to be properly compared by some value is for that value to render one of the trichotomous verdicts-it is a substantial and counterintuitive committment, and one that needs to be justified. I will argue that the orthodox view is deeply unparsimonious.

\footnotetext{
${ }^{9} \operatorname{Raz}(1986)$.

${ }^{10}$ For parity, see Chang (2002). See also Gert (2004), Rabinowicz (2008), Carlson (2010), Elson (2014b) and Andersson (2015a).

${ }^{11}$ Chang (2002), p. 666.
} 


\section{The Vagueness View}

In contrast, the vagueness view gets by with rather limited resources: the trichotomous comparisons, and the possibility of vagueness in their application.

The phenomenon of vagueness has two main 'marks'. In borderline cases, a vague predicate neither clearly applies nor clearly fails to apply. ${ }^{12}$ In classic examples: there are clear heaps of sand, clear non-heaps, and borderline cases, which seem to be 'neither a heap nor not a heap'; there are clearly bald men, clearly non-bald men, and borderline-bald men.

The other mark is the paradox of the sorites, which trades on the apparent truth of tolerance claims such as 'one hair couldn't make the difference between being bald and not-bald', to conclude-paradoxically - that someone with ten thousand hairs is bald, starting from the premise that someone with five hairs is.

The dominant theories of vagueness are that it is indeterminacy, and that it is ignorance. For indeterminists, it is (semantically or metaphysically) indeterminate how many grains are required for a heap, and whether a given borderline-heap is a heap. It is neither determinately true nor determinately false that a borderline-bald man is bald. ${ }^{13}$

Here is the vagueness view:

The Vagueness View of Incommensurability. a and b are incommensurate with respect to some value $\mathrm{V}$ if and only if: it is indeterminate whether $a$ is Ver than $b$, or $b$ is Ver than $a$, or $a$ and $b$ are equally $V$.

It is an interesting question how genuinely evaluative vagueness could arise. One can see how a more broadly dispositional or counterfactual account might go: if the better holiday for Katie is what she would choose under ideal circumstances, for example, then any indeterminacy in this counterfactual will engender indeterminacy in which holiday is better for her. ${ }^{14}$ I set aside this question here, and argue below that evaluative predicates are vague in a way which engenders incommensurability.

If Chang and Raz are the canonical opponents of the vagueness view, then John Broome is its longstanding ally. He has famously argued that incommensurability is vagueness. He argues that vagueness and trichotomous incomparability are not compossible, and that it is implausible that there is no vagueness.

\footnotetext{
${ }^{12}$ Throughout, I stipulatively use 'clear' to mean 'not-borderline'.

${ }^{13}$ A classic presentation of indeterminism is Fine (1975). Recall that I am setting aside epistemicism about vagueness, but little hangs on this.

${ }^{14}$ Compare with Woodward (2012) on incomplete fictions.
} 
The argument's key premise is the collapsing principle:

Collapsing Principle (special version). For any $\mathrm{x}$ and $\mathrm{y}$, if it is false that $\mathrm{y}$ is Fer than $\mathrm{x}$ and not false that $\mathrm{x}$ is Fer than $\mathrm{y}$, then it is true that $\mathrm{x}$ is Fer than $\mathrm{y} .{ }^{15}$

This principle says that there could not be one-sided indeterminacy, where it is determinate that $\mathrm{y}$ is not Fer than $\mathrm{x}$, but indeterminate whether $\mathrm{x}$ is Fer than $\mathrm{y}$, or $\mathrm{x}$ and $\mathrm{y}$ are equally $\mathrm{F}$.

To see this, suppose that there were such a one-sided case: (i) it is indeterminate whether Alice is Fer than Brad, but (ii) determinately, Brad is not Fer than Alice. In other words, it is indeterminate whether Alice is outright Fer than Brad, or merely equally as $\mathrm{F}$ as Brad.

The collapsing principle says that this is incoherent. From (ii), it is false that Brad is Fer than Alice; from (i) it is not false that Alice is Fer than Brad. Thus, by the collapsing principle it must be true that Alice is Fer than Brad, and so (i) is incorrect: the comparison between Alice and Brad in terms of their Fness could not exhibit this kind of 'one-sided' indeterminacy.

I present Broome's argument in an appendix. This argument has structured much of the subsequent debate about incommensurability as vagueness, which has focused on the truth or falsity of the collapsing principle. There has been-to my knowledgeno independent argument for incommensurability as vagueness. The thesis has been hostage to the the collapsing principle.

But this is a mistake, for two reasons. First, that principle is vulnerable to a number of - to my mind-decisive counterexamples. Erik Carlson published the first:

Suppose that we are considering who of Alf and Beth is the better philosopher. Concerning every property that indubitably contributes to goodness as a philosopher, we find that they possess it to an equal degree. However, Alf has greater rhetorical skill than Beth. Does this make Alf a better philosopher than Beth? It seems that there may well be no definite answer to this question. [...] it is definitely false that Beth is a better philosopher than Alf. ${ }^{16}$

This seems a clear case of the 'one-sided indeterminacy' that the collapsing principle forbids. Defenders of the collapsing principle either deny the cogency of such cases, or restrict its scope to avoid them. ${ }^{17}$

\footnotetext{
${ }^{15}$ Broome (1997), p. 74. I follow Broome in omitting 'determinately', here.

${ }^{16}$ Carlson (2004), p. 223.

${ }^{17}$ See Carlson (2004) and Elson (2014a) for counterexamples; Broome (2009), Andersson (2015b) and Constantinescu (2016) offer responses.
} 
Second, even if the principle is true and Broome's argument shows that incommensurability could not be trichotomous incomparability - that (1) is false, in the terminology of the Appendix - this is not yet to show that incommensurability is vagueness.

It is intuitively plausible but has not yet been shown - to my knowledge-that vagueness can account for the main features of incommensurability, or even that it can satisfy the relatively standard definition of incommensurability provided above. Perhaps this is simply obvious, but in the remainder of this paper, I argue that it is true, and I defend the vagueness view without appeal to the collapsing principle.

\section{Vagueness without Collapse}

The first task is to show how vagueness (specifically: borderlineness) engenders incommensurability.

We must distinguish two kinds of borderline case. The most familiar are categorical: it is indeterminate whether some monadic predicate such as 'is bald' or 'is a heap' applies. The question 'is a F?' has no determinate answer.

In comparative borderline cases, however, the relevant question is, for some predicate $F$ and two objects a and b, 'is a Fer than b?'. At least two of ' $a$ is Fer than b', ' $b$ is Fer than $a$ ', and ' $a$ and $b$ are equally $F$ ' are indeterminate. According to the vagueness view, when $\mathrm{F}$ is an evaluative predicate, such cases engender or ground incommensurability.

Comparative borderline cases arise in two ways.

First, many predicates are multidimensional: they depend for their application on multiple contributory factors, and there is a relative weighting (or 'exchange rate') between them. ${ }^{18}$ The predicate 'is bald' is multidimensional: its application is determined not only by hair numbers, but colour, thickness, and distribution.

The 'exchange rate' terminology makes clear what we are talking about: if we remove fifty of Hank's hairs, how much must we thicken his remaining hairs to make him precisely as bald as before? Similarly, if we take $\$ 50$ from Hank, then the exchange rate between US Dollars and Swedish Krona will determine how many Krona we must give him to render him precisely as wealthy as before. (A downside of the 'exchange rate' and 'relative weighting' terminology is that it suggests that the dimensions are weighted linearly against each other. This need not be so.)

\footnotetext{
${ }^{18}$ The 'exchange rate' terminology is from Lewis (1994), p. 479. For discussion of multidimensional predicates, see Alston (1964), pp. 87-90. I'm grateful to an anonymous reviewer for suggesting the Alston text.
} 
When the exchange rate is vague, this multidimensionality engenders comparative borderlineness. Suppose that Hank has fewer hairs, but they are thin and widely distributed over his head. But Henry has more and thicker hairs concentrated in a ring around his scalp. It may be indeterminate whether Hank is balder, or Henry is balder, or they are precisely equally bald. Similarly, if the dollar-krona exchange rate were vague, then it could be indeterminate whether Hank is now richer, poorer, or precisely as wealthy as before.

Vague exchange rates are ubiquitous. When we are required to score something along multiple dimensions, we might assign precise weights to those dimensions for calculative purposes, but this is often an arbitrary exercise. To take an example in the spirit of Carlson, if we are hiring a philosopher we may have to stipulate that research output contributes exactly one-third of goodness as a candidate for our department. (This may be done implicitly, by scoring the candidates on a form which has research output, teaching quality, and administrative experience as the three dimensions of evaluation, without any specified weighting.)

Second, comparative borderlineness may also be derivative of categorical borderlineness, where the application of a comparative predicate depends on the application of a non-comparative predicate. For example, the fairly ordinary predicate 'military-aged man' has categorical borderline cases. Suppose that any 57 year-old man is borderline military-aged, and that we wish to compare countries by their military strength, using the predicate 'is militarily strong', the application of which is determined by the military-aged male population.

Suppose that two countries, A and B, have similar populations, except:

- A has 20,000 more 57 year-old men than B;

- B has 10,000 more 50 year-old men than A.

The 50 year-olds are clearly military-aged, whereas the older men are borderline military-aged. So it is vague whether A has more or less military-age men than B, and so it is vague which country is militarily stronger. This comparative borderline case does not depend on a vague exchange rate, or any multidimensionality. If one accepts the existence of ordinary categorical borderline cases, one must also accept their comparative cousins.

On the vagueness view, value incommensurability is simply the evaluative instance of comparative vagueness. For two options to be incommensurate with respect to some value $\mathrm{V}$ is for them to be a comparative borderline case of Vness: it is indeterminate which of the trichotomous comparisons obtains between them.

In such a comparative borderline case of an evaluative predicate, it is not determinately true that one option is better with respect to that value, that the other is better, or that 
they are equally good. None of the trichotomous comparisons determinately applies, and this satisfies our definition of incommensurability.

But the vagueness view does face a problem here, and one which is exacerbated by the loss of the collapsing principle. The view claims that all evaluative comparative vagueness engenders incommensurability. ${ }^{19}$ But not all borderline cases look like 'classic' instances of incommensurability. It can happen that one of the three trichotomous comparisons clearly fails to apply. (But only one: if two clearly failed to apply, then the third would clearly apply, and the case would not be borderline.)

This is perhaps not troubling when it is indeterminate whether a is better or worse than $\mathrm{b}$, but clear that they are not equally good. (The military strength of A and B is like this.) Similar decision-theoretic puzzles apply here as in 'core' cases of incommensurability.

But what about 'one-sided' cases? Carlson's example of the goodness of philosophers is like this: it's indeterminate whether Alf is better than Beth or merely equally as good as her, but clear that he is not worse than her. This kind of one-sided indeterminacy would be ruled out by the collapsing principle. But on the vagueness view, this indeterminacy is coherent and renders Alf and Beth incommensurate.

We should-whilst acknowledging a certain awkwardness-accept the vagueness view's implication that there are such cases of 'one-sided' incommensurability. These cases too raise decision-theoretic puzzles: is it permissible to hire Beth? It isn't clear, and a theory of the incommensurate seems to be as good a place as any to seek an answer to this question. ${ }^{20}$ It is a virtue of the vagueness view that it brings such puzzling cases under a single theoretical umbrella.

So-with some awkwardness - vagueness explains the formal structure of incommensurability.

\section{The Shifted Burden}

This is enough to make it a candidate theory of the phenomenon, but why prefer it to the others? It is at this point that we shift the burden. Where other accounts posit a sui generis evaluative phenomenon (to my knowledge, none posits trichotomous incomparability in non-evaluative comparisons), the vagueness view explains incommensurability as the evaluative manifestation of an everyday—if paradoxical—phenomenon.

\footnotetext{
${ }^{19} \mathrm{I}$ 'm grateful to an anonymous reviewer for highlighting how tendentious this claim is.

${ }^{20}$ Broome (1997) thinks it would not be permissible, and defends the collapsing principle on this basis.
} 
The burden then is this: why accept trichotomous incomparabilism? There are several strategies available to the opponent. The principal ones are:

(1) The vagueness-denial strategy. Though vagueness would engender something like incommensurability, evaluative predicates are not (or are not suitably) susceptible to vagueness.

(2) The indistinguishable phenomena strategy. Though we cannot tease them apart, both vagueness and trichotomous incomparability occur.

(3) The distinctive phenomena strategy. Though vagueness can generate something similar to incommensurability, closer investigation shows that it cannot account for all instances, and thus a further phenomenon (trichotomous incomparability) must be posited.

I won't discuss the indistinguisable phenomena strategy. It seems to me that no evidence could be offered in its support, and that similarly nothing can be said against it, other than appeals to philosophical parsimony. What grounds could we have to accept this theory?

The vagueness-denial and distinctive phenomena strategies present more substantial challenges. I discuss them in turn.

\section{Against vagueness-denial}

Most ambitiously, the opponent might deny that evaluative predicates are vague in the way required for incommensurability. I will argue that this is a non-starter, for two reasons: the supervenience of the evaluative on the non-evaluative, and the application of standards from the wider vagueness literature.

Unless we're being really radical, we must accept that there is widespread nonevaluative vagueness. But the application of an evaluative predicate will often supervene on that of a non-evaluative predicate. A short argument shows that in such cases, the evaluative predicate, too, must be vague.

Let the application of the evaluative predicate 'is stingy' supervene on that of the non-evaluative predicate 'is rich'. The case I have in mind is this: holding constant everything else (such as charitable donations) whether someone is stingy depends on how rich she is: for a poor person to donate precisely $£ 5$ per month is not stingy, but for a rich person to do so is.

Now let the non-evaluative 'is rich' be vague. Suppose that Pauper is clearly not-rich, King is clearly rich, Merchant is borderline-rich, and each donates $£ 5$ per month to 
charity. King is clearly stingy, and Pauper is clearly not stingy. What about Merchant?

There are three options: either Merchant is clearly stingy, clearly not-stingy, or borderline-stingy.

If Merchant is clearly stingy, then it is indeterminate whether supervenience has been violated (because it is indeterminate whether she is stingy despite not being rich). Similarly, supervenience is indeterminately-violated if she is clearly not stingy. The only possibility for preserving supervienience as a clear truth is that Merchant is borderlinestingy, and so the evaluative predicate 'is stingy' is vague.

To put the point more generally but more technically: if we wish to preserve links between evaluative and non-evaluative predicates as 'penumbral connections' in the words of Fine (1975) - and supervenience suggests that we do-then any vagueness in one must be matched by vagueness in the other.

The second reason turns on the standards prevalent in philosophical discussions of (non-evaluative) vagueness. To take a representative example, and focusing on borderlineness, David Braun and Ted Sider claim that 'an expression is vague if it can be unclear to a speaker informed of all relevant facts whether the expression correctly applies. ${ }^{21}$

Many evaluative predicates clearly meet this standard. For example, consider the thick evaluative concept of cowardice. ${ }^{22}$ What is the precise minimum number of people one must be prepared to fight in order to be a non-coward? Is it more cowardly to run from a single man armed with a shotgun, or from a dozen men armed with just their fists? Whatever standards we use for attributing vagueness in ordinary cases seem to apply here.

Evaluative vagueness has been a focus of both historical and recent philosophical discussion. ${ }^{23}$ Denying that it exists is not a promising way for Trichotomous Incomparabilism to discharge the explanatory burden.

\subsection{Distribution}

A less ambitious-and more promising - approach is to argue that though evaluative predicates are vague, they are not vague in the right ways or places to account for the distribution of incommensurability.

Joseph Raz suggests an argument along these lines:

\footnotetext{
${ }^{21}$ Braun and Sider (2007), p.133.

${ }^{22}$ I'm grateful to Nate Sharadin for the example.

${ }^{23}$ See, for example, Aqvist (1964) and Dougherty (2014).
} 
The most important source of incomparability is 'incomplete' definition of the contribution of the criteria to value. [...] It is possible that our way of weighting the different criteria does not establish a different ranking of all possible combinations. [...] There are at least two other sources of incomparability. First, indeterminacy results from vagueness and the absence of sharp boundaries which infects language generally and therefore apply to value measured by a single criterion as well. These apply even in cases in which a single descriptive criterion determines the value of options... ${ }^{24}$

This is recognisably an attempt to discharge the explanatory burden, by arguing that vagueness is not the only 'source' of the phenomenon. But it can only succeed if the 'indeterminacy [that] results from vagueness and the absence of sharp boundaries which infects language generally ...' must be distinct from the " 'incomplete definition' of the contribution of the criteria to value".

I have argued that the latter is naturally characterised as a species of the former, once we consider the possibility of vague exchange rates.

As for the claim that vagueness can arise even without multidimensionality, this is clearly correct: if the number of military-age men is the sole dimension relevant to the comparative military strength of countries, then A and B are a comparative borderlinecase of the (unidimensional) predicate 'is militarily stronger'. Were this to be treated as an evaluative comparison, then $\mathrm{A}$ and $\mathrm{B}$ are incommensurate with respect to their military strength.

I do not find this implausible, for reasons that are now familiar. Most importantly, the same decision-theoretic issues arise here as in 'core' cases of incommensurability. If one were seeking to join the militarily strongest country, how would one choose in this case?

Nevertheless, it is true that incommensurability bears a close connection to multidimensionality, and in particular to 'Pareto-mixed' comparisons, where one option is 'better in some ways, and worse in others.' 25

This is neatly explained by appeal to vagueness: as we have seen, multidimensionality means that the different dimensions must be weighted against each other, and this 'exchange rate' provides a locus of vagueness, because the exchange rate may be vague. It is difficult to have a multidimensional predicate that does not engender comparative borderline cases, because the exchange rate between the dimensions must be wholly

\footnotetext{
${ }^{24} \operatorname{Raz}$ (1986), p. 122.

${ }^{25} \mathrm{I}$ am indebted to anonymous reviewers for immensely helpful comments on the argument of this section.
} 
precise to avoid such cases.

Incommensurability is incompatible with a clear lack of Pareto-mixing: if one option is clearly at least as good along every dimension, then it is clearly at least as good all things considered.

But even clear Pareto-mixing is not sufficient for incommensurability. In many Paretomixed comparisons, one option is nevertheless better. For example, if Churchill were only $5 \mathrm{kr}$ more expensive than Florida, but markedly superior in every other way, we should not hesitate to say that Churchill is better than Florida.

To see how the vagueness view can explain this, let's construct a toy model of this comparison. Suppose that the only two dimensions relevant to the choice are price $(\mathrm{P})$ and adventure (A). Then each holiday will earn a score (S). For example, where the subscript ' $F$ ' denotes Florida (and 'C' Churchill):

$\mathrm{S}_{\mathrm{F}}=\alpha \mathrm{P}_{\mathrm{F}}+\mathrm{A}_{\mathrm{F}}$

Here ' $\alpha$ ' then represents the exchange rate between price and adventure: if $\alpha$ is 0.5 , then adventure is twice as important, and so on.

According to the vagueness view, then, incommensurability will often occur when the exchange rate $\alpha$ is vague. If it is vague whether $\alpha$ is 0.5 or 0.6 , then Churchill and Florida will be incommensurate if $\mathrm{S}_{\mathrm{F}}>\mathrm{S}_{\mathrm{C}}$ when $\alpha=0.5$, and $\mathrm{S}_{\mathrm{F}}<\mathrm{S}_{\mathrm{C}}$ when $\alpha=0.6$.

But there will be some holidays (those that are both expensive and unexciting) such that Churchill 'wins' on both values of $\alpha$. This is just the familiar observation that vague predicates-including comparatives-also have clear cases.

Thus the vagueness view explains why we can have Pareto-mixing without incommensurability most commonly in the following two sorts of cases. First, when one dimension of comparison is much more important than the others (ie, when $\alpha$ is very high or very low). Second, when the dimensions are roughly equal in importance, but one option is much stronger along one dimension, and only slightly weaker than the other in another dimension.

This is not to say that competing accounts cannot tell a story about the connection between multidimensionality, Pareto-mixing, and incommensurability. But vagueness provides a neat theoretical framework for such a story.

The vagueness view also explains why under Pareto-mixing, incommensurability and betterness and worseness are each common, but equal goodness is rare. It is very unusual to find a case where though two options are Pareto-mixed, they are precisely equally good. On the vagueness view, not only $\alpha$ but also the respective values of $\mathrm{P}$ 
and A would have to be fixed precisely, to determinately 'balance out' for clear equal goodness.

\subsection{Purely Ordinal Rankings?}

I have been arguing that vagueness neatly explains why incommensurability arises, where it arises. A promising strategy for the opponent would be to present a case where there is clearly incommensurability, but no locus of vagueness to which it might be traced.

Sports may seem to offer an example of this. In many sporting competitions there are several individual events, each of which contributes to the overall rankings: what if all we have to go on is each competitor's ordinal rank in each event? ${ }^{26}$ In such cases, we would need more than simply a vague 'exchange rate' between dimensions to generate incommensurability via vagueness, since there may be no cardinal values to be exchanged. ${ }^{27}$

There is nothing incoherent about such wholly ordinal evaluative structures, which would give rise to a form of trichotomous incomparability. The question is whether any actual evaluative practices have this structure. Here are two reasons to doubt that they do.

First, apparent examples seem to dissolve upon closer inspection. Even in sports, even when each dimension is genuinely ordinal-for example, finishing position in a racecardinal values and an exchange rate are arbitrarily imposed for the purposes of comparison: 6 points for first place, and so on.

The structure of such rankings suggest that the underlying evaluation ('is a better racer') has more than just the kind of ordinal content that would ground a counterexample to the vagueness view. In racing for example, it is plausibly an evaluative truth that the difference between first and second place is more important than that between thirty-first and thirty-second.

Second, such an evaluative structure would lack the features described in the previous subsection. On this structure, any Pareto-mixed comparison would be trichotomously incomparable and therefore incommensurate. But as we have seen, this seems not to be the case-many Pareto-mixed comparisons are not incommensurate.

\footnotetext{
${ }^{26}$ See Sinnott-Armstrong (1985), especially p. 327. I am grateful to Walter Sinnott-Armstrong for this line of objection, and for the sporting example.

${ }^{27}$ See Okasha (2011) for an intriguingly parallel discussion of weighting competing theoretical virtues in scientific theory-choice.
} 
I therefore tentatively conclude that the vagueness-denial strategy has not been successfully carried out: there seems to be vagueness 'available' to account for cases of incommensurability.

\section{Vagueness and Arbitrary Choice}

The distinctive phenomena strategy has been pursued by Ruth Chang, who has influentially argued that vagueness views cannot account for distinctive features of one-shot choices involving incommensurate comparisons, which she calls 'superhard. ${ }^{28}$ Chang argues that disagreement in the face of incommensurability is subject to substantive dispute, but disagreement in the face of vagueness can be stipulated away.

In effect, she accepts the Arbitrary Choice Thesis for vagueness, but not for the incommensurate:

in borderline cases, it is perfectly permissible to resolve the indeterminacy in favour of application or not by arbitrary stipulation, but in superhard cases, resolution of the perplexity in context-free cases is not permissibly given by arbitrary stipulation. ${ }^{29}$

If this is right, then incommensurability and vagueness have different resolution conditions in one-shot cases, and incommensurability could not be vagueness. She introduces a neat thought experiment, to abstract from any potentially distorting context. Jack is playing a game, and must sort people into a 'bald' or a 'non-bald' pile. Players of the game are fully informed, Herbert is borderline-bald, and Jack must choose a pile for him; Jack sorts Herbert into the 'bald' pile. Then:

What is crucial is that the sorting decision is perfectly arbitrary; he could just as well have flipped a coin to determine how Herbert was to be sorted [...] if we add another player, Jill, who happens to sort Herbert into the 'not bald' pile, Jack and Jill have no real disagreement; their 'disagreement' is simply a clash of arbitrary stipulations in the face of indeterminate application. Of course, this is not to say that the answer to the question, Is Herbert bald, is given by a coin flip, for the answer to that question is that it is indeterminate whether he is. The point here is only that a resolution of this indeterminacy can be appropriately given by a

\footnotetext{
${ }^{28}$ This is not Chang's only use of the distinctive phenomena strategy; she also appeals to phenomenological considerations. But I think Ryan Wasserman's response to this is decisive, so I won't discuss it here. See Wasserman (2004) p. 398.

${ }^{29}$ Chang (2002) pp. 679-688.
} 
coin flip. In general, the resolution of borderline-cases can always be a matter of arbitrary stipulation. ${ }^{30}$

If 'resolution' is interpreted in terms of deciding what to $d o$, then Chang's claims here are clearly correct. If it is indeterminate which pile Herbert must go into, but determinate that he must go into one, then what is there to do, but stipulate arbitrarily? By hypothesis, there is no determinate reason to choose one over the other. Whatever you do, it will be indeterminate whether you have put him in the correct pile.

Here 'arbitrary stipulation' need not be limited to random picking, such as coin flips. One can adopt a general policy to deal with borderline cases, such as putting the tall borderline-bald men into one pile, and the not-tall in another. The point is that the rules of the game do not specify into which pile Herbert should go, so we must appeal to something 'outside the rules', so to speak. This will be arbitrary from the perspective of the rules.

Chang claims that when facing a superhard case, we need not resort to such arbitrary stipulation:

The resolution of perplexity in superhard cases is very different in nature. Suppose that Jack is confronted with the superhard case involving Mozart and Michelangelo. The rules of the game require him to put the ordered pair in one pile or the other ... what is crucial is that his decision is not properly arbitrary; it is not true that the could just as well have a flipped a coin to resolve the perplexity. If Jill puts the pair in (the other pile), Jack and Jill have a genuine disagreement over whether Mozart has the greater creativity - this is no clash of arbitrary decisions but a substantive disagreement in which arguments can be brought to bear. ${ }^{31}$

We must admit that there is a difference here. But I will argue that it arises not because one case is superhard and the other vague. Instead, superhardness is vagueness, and the cases differ in some other way.

If the Mozart/Michelangelo comparison is superhard, then the disagreement between Jack and Jill cannot be substantive in the way Chang suggests. If Mozart and Michelangelo are incommensurate, and Jack and Jill are fully-informed, then they will agree that the case is superhard, and thus that it is not true that Mozart is more creative, or that Michelangelo is more creative, or that they are equally creative.

But then how could resolution be a matter of substantive debate between them? Suppose that Jack thinks that it would be better to choose Mozart, solely on the grounds of creativity: does that not imply that he thinks that Mozart is more creative? It is

\footnotetext{
${ }^{30}$ Chang (2002), p. 684.

${ }^{31}$ Chang (2002), pp. 684-5.
} 
incoherent to think that Mozart and Michelangelo are incommensurate with respect to creativity, but that on substantive grounds of creativity, Mozart should be put in the 'more creative' pile: why don't those substantive grounds render him more creative than Michaelangelo, and not merely incommensurate with him?

In general, it's untenable for Jack and Jill to agree that the Mozart/Michaelangelo comparison is superhard, yet to have a 'substantive dispute' about how they should be classified.

Note that this is not a case of them thinking that there is a hidden (trichotomous) fact of the matter, and perhaps having substantive grounds for judging it more probable that Mozart is better than that Michaelangelo is better. This is also incompatible with judging them trichotomously incomparable.

Firm intuitions are scarce here, but to switch examples, it seems plainly incoherent for Katie to think both that (i) the two holidays are incommensurate as a holiday for her, and neither is better; and (ii) that on substantive grounds concerning which is a better holiday for her, she ought to choose Churchill, and that were her travel partner to choose Florida, they would have a substantive disagreement. Instead, Simon Blackburn seems to be correct that incommensurability often demands arbitrary stipulation, and that "both common sense and high theory tell us how to handle it. The agent has to plump for one alternative. ${ }^{32}$

Ryan Wasserman rightly claims that Chang 'has put her finger on a very common intuition here ... [in evaluative cases] I find myself hesitant to conclude that there is no relevant fact of the matter. ${ }^{33}$ But this is perhaps overly concessive to the intution: to judge a pair incommensurate is to judge that there is no such (determinate) fact, if that means that none of the trichotomous comparisons obtains.

There is of course much more room for debate about whether the Mozart/Michelangelo pair is superhard than there is in the baldness case, for several reasons. There is more at work in the complex notion of creativity than in the largely observational 'is bald'. As Cristian Constantinescu and others have pointed out, there are many differences between the cases. ${ }^{34}$ Whereas 'is bald' is a monadic predicate that applies to individuals, 'is more creative than' is a dyadic comparative predicate that applies to pairs. The application of 'is bald' is determined by perhaps a few dimensions-hair number, distribution, colour, thickness-where the first and second are by far the

\footnotetext{
${ }^{32}$ Blackburn (2010), p. 50.

${ }^{33}$ Wasserman (2004), p. 400.

${ }^{34}$ See Constantinescu (2012). But his own preferred explanation-that 'the application of vague predicates can seem less arbitrary not because those predicates are any less vague, but simply because it matter to us more in those contexts how we apply the relevant predicates' (p. 62) — can't be the whole story. Stipulatively, here we are dealing with a game, which rules out contextual factors like importance.
} 
most important; the application of 'is more creative than' is certainly determined by many more dimensions (there may not even be a determinate list, if the predicate has 'open texture'). And whilst 'is bald' is normally a nonevaluative predicate, 'is more creative than' is straightforwardly evaluative.

The cases have little in common, other than that Jack and Jill face perplexity about the application of a predicate. This pair of cases is not a good test for whether the presence of superhardness (as opposed to mere vagueness) changes the resolution conditions. A genuine test will have to hold as much else fixed as possible.

In the United States, admission to most selective undergraduate colleges is determined by several dimensions, including exam scores, essays, letters of recommendation, extracurricular activities such as sport and volunteering, and money. ${ }^{35}$ Jess and John are paid to play a game: they must select candidates for a given university. They must put candidates into one of two piles: accept, or reject. They have one slot left, and two remaining candidates, $\mathrm{a}$ and $\mathrm{b}$. The candidates are roughly equal in most respects, but for the following differences: a has test scores about $5 \%$ better; $b$ has done somewhat more hours of volunteering. In light of this, is is not clear who should get the slot.

There are two ways that Jess and John's game might be run. The first leaves significant room for them to exercise judgement:

Admissions as Superhard. Jess and John have instructions to 'admit the best candidates'.

They are working to decide who is the better candidate, which is a plainly evaluative task: $\mathrm{a}$ is better in one way, and $\mathrm{b}$ is better in another, but which is better overall? The choice is superhard. Since Jess and John are in an institutional role, and have no other incentives either way, in certain circumstances their choices will be determined purely by the evaluative considerations. They are making a good-faith effort to admit the best candidates.

But the game may also be structured so as to involve vagueness:

Admissions as Vague. Jess and John are working from an instruction sheet. The sheet contains the instruction, 'admit candidates with higher test scores, unless they have done substantially fewer volunteering hours'.

Under the new management, Jess and John are explicitly told to avoid evaluative judgements about who is the 'better' candidate. Instead they are simply judging whether a certain multidimensional predicate applies, in a fairly mechanical way: scoring candidates along multiple dimensions, and calculating an overall score according to some

\footnotetext{
${ }^{35}$ Compare with Seung and Bonevac (1992), pp.806-809. I'm grateful to anonymous reviewers for comments on a previous version of this case.
} 
specified weighting. But 'substantially fewer volunteering hours' is vague: depending on context, 10 hours over a year might be borderline-substantial, and a difference of 0.01 hours seems liable to ground a sorites on 'substantially fewer'.

If the $\mathrm{a} / \mathrm{b}$ pair is a comparative borderline case of the criterion 'higher scores without substantially fewer volunteer hours', then then it is vague what the instructions require. This might be compared to a case of legal vagueness.

Admissions as Superhard and Admissions as Vague are structurally similar. If Chang's resolutional argument were correct, the differences she describes-that in one case resolution is arbitrary and stipulative, in the other case substantive-should arise here too. But they don't seem to. Intuitively, in both versions of Admissions, arbitrary choice is permissible, even required. What other way is there to proceed? In both cases, the Jess and John agree that the rules of the game do not determine which candidate to admit. How are they to fill the slot if they do not go 'beyond the rules' by choosing arbitrarily in some sense?

No striking difference in acceptable resolution methods between the superhard and the borderline seems to manifest here. The best explanation of this is that resolution in the Mozart/Michelangelo case is also arbitrary, and any appearance to the contrary can be explained by the special features of that case.

Incommensurability and vagueness both seem to bring arbitrariness. Indeed, the vagueness view promises to (partially) explain the permissibility of arbitrary choice in the face of incommensurability, because choice under incommensurability simple is choice under vagueness. The latter phenomenon arises otherwise, whether from vague utility or credence functions, or from vagueness concerning such matters as personal identity. Nearly all current discussion of rational choice under vagueness supports the permissibility of random, arbitrary, or 'capricious' choice. Some views even require that choice be truly randomised. ${ }^{36}$ (If the vagueness view is correct, many of these situations involve incommensurability.)

There may be more 'broadly pragmatic' reasons to be wary of coin-flipping when the moral or evaluative stakes are high. Perhaps coin-flipping would fail to show due deference to morality, or in cases of legal vagueness, to the law. But it doesn't follow that there is a non-arbitrary way to proceed. As Simon Blackburn notes, some such arbitrary picking methods—such as cards, or drawing straws—do carry an air of seriousness. ${ }^{37}$ The culturally-contingent connotations of some methods of arbitrary stipulation do not amount to evidence that arbitrary stipulation is per se inappropriate.

\footnotetext{
${ }^{36}$ Williams (2014).

${ }^{37}$ Blackburn (2010), p. 50.
} 
The Vagueness View offers a plausible decision theory in 'one-shot' choices between incommensurate options: choose arbitrarily.

\section{Conclusion: Incommensurability and Vagueness}

I have outlined a view according to which all evaluative comparative vagueness (specifically: borderlineness) engenders incommensurability, and all incommensurability is evaluative comparative vagueness. The view is defended without appeal to the collapsing principle.

More broadly, I have argued that vagueness offers a parsimonious account of incommensurability, and that the vagueness view's fate need not be tied to the collapsing principle. Moreover, the opponent faces the following question: if it is true that there is widespread evaluative vagueness, and that — as I have argued — this engenders a phenomenon much like incommensurability, then where is it all? Why posit a sui generis evaluative phenomenon when vagueness will do?

Once we look at incommensurability and vagueness through this lens, we see the enormous structural and theoretical similarities between them. Incommensurability engenders phenomenal instability, and so does vagueness. It can be difficult to hold in one's head the verdicts that make up a judgement of incommensurability ( $\mathrm{a}$ is neither at least as good as b nor worse than $b$, but a and $b$ are properly compared); it can be difficult to hold in one's head the verdicts that make up a judgement of borderlineness (Herbert is a man with hair on his head, but he is neither bald nor not-bald). Even the range of theoretical options-indeterminacy and eliminativism/epistemicism—is similar.

But like everyone else, I lack a convincing theory of value-pumping. It seems that mainstream Trichotomous Incomparabilism must simply stipulate restrictions against it. Here, for example, is Chang:

The rational permissibility of choosing either of two items on a par, then, must be constrained by one's other choices. If one chose B when offered a choice between $\mathrm{A}+$ and $\mathrm{B}$, one is thereby rationally prohibited from choosing A when offered a choice between B and A. [...] The air of paradox is dispelled once we see that the sense in which it may be rationally impermissible to choose one of two items on a par depends on understanding the rationality of choice against a background of other choices. ${ }^{38}$

\footnotetext{
${ }^{38}$ Chang (2005), p. 347.
} 
Without argument, such a constraint seems unacceptably ad hoc (notice that similar constraints do not apply to choice under betterness, worseness, and equal goodness).

On the vagueness view, however, decision-making under incommensurability is assimilated to that under vagueness. This is philosophically fruitful: the phenomenon of value-pumping occurs in many cases of rational choice under vagueness. These include Warren Quinn's Puzzle of the Self-Torturer, and 'vague projects', which have imprecise satisfaction conditions. ${ }^{39}$ Vagueness at least provides a framework for theorising about the problem.

The vagueness view lacks a decisive advantage over Trichotomous Incomparabilism on this issue. But the vagueness view is superior along several other dimensions, and seems to be worse along none. So its denial requires a justification.

This argument of this paper does not promise to be decisive in the way that Broome's does. The collapsing principle implies that trichotomous incomparability and vagueness are not compossible; the present argument has a somewhat similar structure, but does not rule out 'cohabitation' between the phenomena. Instead, having both seems unparsimonious. Rather than saying that one must choose, my claim is that we have good—and undefeated—reason to think that there is no trichotomous incomparability, and that incommensurability is vagueness.

\section{Appendix: Broome's Argument}

To formulate the argument, we use a 'standard configuration', where some object (the standard) is compared with a range of objects of some other kind. Let us suppose that are comparing careers, and the relevant virtues include — but are not limited to-salary. By way of reductio, suppose that there is an instance of trichotomous incomparability:

(1) The philosophy job A (the standard) is trichotomously incomparable with a range $\mathrm{B}_{100}, \ldots, \mathrm{B}_{150}$ of banking jobs.

Here the subscripts denote the salary of the banking job (which are otherwise identical). Suppose (also for reductio) that there are borderline cases of such trichotomous incomparability:

(2) It is indeterminate whether the banking job $\mathrm{B}_{151}$ is trichotomously incomparable with A, or outright better than A.

\footnotetext{
${ }^{39}$ See Quinn (1990); Tenenbaum and Raffman (2012); Williams (2014); Moss (2015); Rinard (2015); Elson (2016).
} 
Then it is not false that $B_{151}$ is better than $A$. But it is false that $A$ is better than $B_{151}$, because $B_{151}$ is better than $B_{150}$, and it is false that $A$ is better than $B_{150}$. (Intuitively: if the philosophy job is not better than a given banking job, it is certainly not better than that same banking job with a higher salary.)

Applying the collapsing principle, it is true that $\mathrm{B}_{151}$ is better than $\mathrm{A}$. Reductio: $\mathrm{B}_{151}$ could not have been borderline-incommensurate with A after all.

Thus (1), (2), and the collapsing principle form an inconsistent triad. No region of trichotomous incomparability could have 'vague edges' of this sort, because the collapsing principle rules out borderline cases of 'is trichotomously incomparable with A'.

Assuming the truth of the collapsing principle, (1) or (2) must be abandoned. Since it's highly implausible that there could not be vagueness at the edges of any trichotomous incomparability, Broome argues, we should abandon (1), the claim of trichotomous incomparability.

\section{References}

Alston, W P. 1964. Philosophy of language. Prentice-Hall Foundations of Philosophy Series. Prentice-Hall.

Andersson, Henrik. 2015a. "Parity and Comparability-a Concern Regarding Chang's Chaining Argument." Ethical Theory and Moral Practice. doi:10.1007/s10677-015-9621-5.

2015b. "Propping Up the Collapsing Principle." Ethical Theory and Moral Practice 18 (3): 475-86. doi:10.1007/s10677-014-9533-9.

Aqvist, Lennart. 1964. "Vagueness and Value." Ratio 6 (2): 121-27.

Blackburn, Simon. 2010. "Dilemmas: Dithering, Plumping, and Grief." In Practical Tortoise Raising, edited by Simon Blackburn, 47-63. Oxford: Oxford University Press. doi:10.1093/acprof:oso/9780199548057.001.0001.

Braun, David, and Theodore Sider. 2007. "Vague, so Untrue." Nous 41 (2). Blackwell Publishing Inc: 133-56. doi:10.1111/j.1468-0068.2007.00641.x.

Broome, John. 1997. "Is incommensurability vagueness?” In Incommensurability, Incomparability, and Practical Reason, edited by Ruth Chang, 67-89. Harvard University Press.

2009. "Reply to Rabinowicz." Philosophical Issues 19 (1): 412-17. 
doi:10.1111/j.1533-6077.2009.00175.x.

Carlson, Erik. 2004. "Broome's Argument against Value Incomparability." Utilitas 16 (2): 220-24. doi:10.1017/S0953820804000548.

2010. "Parity Demystified." Theoria 76 (2). Blackwell Publishing Ltd: 11928. doi:10.1111/j.1755-2567.2010.01063.x.

Chang, Ruth. 2002. "The Possibility of Parity." Ethics 112 (4): 659-88. http://www. jstor.org/stable/10.1086/339673.

- 2005. "Parity, Interval Value, and Choice." Ethics 115 (2): 331-50. doi:10.1086/426307.

Constantinescu, Cristian. 2012. "Value Incomparability and Indeterminacy." Ethical Theory and Moral Practice 15 (1): 57-70. doi:10.1007/s10677-011-9269-8.

—. 2016. "Vague Comparisons." Ratio.

Dougherty, Tom. 2014. "Vague Value." Philosophy and Phenomenological Research 89 (2): 352-72. doi:10.1111/phpr.12026.

Elson, Luke. 2014a. "Borderline Cases and the Collapsing Principle." Utilitas 26 (01): 51-60. doi:10.1017/S095382081300023X.

- 2014b. "Heaps and Chains: Is the Chaining Argument for Parity a Sorites?" Ethics 124 (3): 557-71. doi:10.1086/674844.

- 2016. "Tenenbaum and Raffman on Vague Projects, the Self-Torturer, and the Sorites." Ethics 126 (2): 474-88. doi:10.1086/683533.

Fine, Kit. 1975. "Vagueness, truth and logic." Synthese 30 (3): 265-300.

Gert, Joshua. 2004. "Value and Parity." The University of Chicago Press. doi:10.1086/381697.

Lewis, David. 1994. "Humean Supervenience Debugged." Mind, New series, 103 (412). Oxford University Press on behalf of the Mind Association: pp.473-490. http: //www.jstor.org/stable/2254396.

Moss, Sarah. 2015. “Credal Dilemmas.” Noûs 49 (4): 665-83. doi:10.1111/nous.12073.

Okasha, Samir. 2011. "Theory Choice and Social Choice: Kuhn versus Arrow." Mind 120 (477): 83-115. doi:10.1093/mind/fzr010.

Quinn, Warren S. 1990. "The Puzzle of the Self-Torturer.” Philosophical Studies 59 (1). Kluwer Academic Publishers: 79-90. doi:10.1007/BF00368392.

Rabinowicz, Wlodek. 2008. "Value relations." Theoria 74 (1): 18-49. 
doi:10.1111/j.1755-2567.2008.00008.x.

Raz, Joseph. 1986. "Value incommensurability: some preliminaries." Proceedings of the Aristotelian Society, New Series 86: 117-34.

Regan, Donald. 1997. "Value, Comparability, and Choice." In Incommensurability, Incomparability and Practical Reason. Harvard University Press.

Rinard, Susanna. 2015. "A Decision Theory for Imprecise Probabilities.” Philosophers' Imprint 15 (7): 1-16.

Seung, T K, and Daniel Bonevac. 1992. "Plural Values and Indeterminate Rankings." Ethics 102 (4): 799-813. http://www.jstor.org/stable/2381555.

Sinnott-Armstrong, Walter. 1985. "Moral Dilemmas and Incomparability." American Philosophical Quarterly 22 (4): 321-29.

Sousa, Ronald B de. 1974. “The good and the true.” Mind 83 (332). JSTOR: 534-51.

Tenenbaum, Sergio, and Diana Raffman. 2012. "Vague Projects and the Puzzle of the Self-Torturer." Ethics 123 (1): 86-112. doi:10.1086/667836.

Wasserman, Ryan. 2004. "Indeterminacy, Ignorance and the Possibility of Parity." Philosophical Perspectives 18 (1). Blackwell Publishing Ltd/Inc.: 391-403. doi:10.1111/j.1520-8583.2004.00034.x.

Williams, J Robert G. 2014. “Decision-Making Under Indeterminacy.” Philosophers' Imprint 14 (4): 1-34.

Woodward, Richard. 2012. "Fictionalism and incompleteness." Nous 46: 781-90. doi:10.1111/j.1468-0068.2010.00826.x. 